NASA Technical Memćrandum 100101

AIAA-87-9034

\title{
Development of an Advanced Photo- voltaic Concentrator System for Space Applications
}

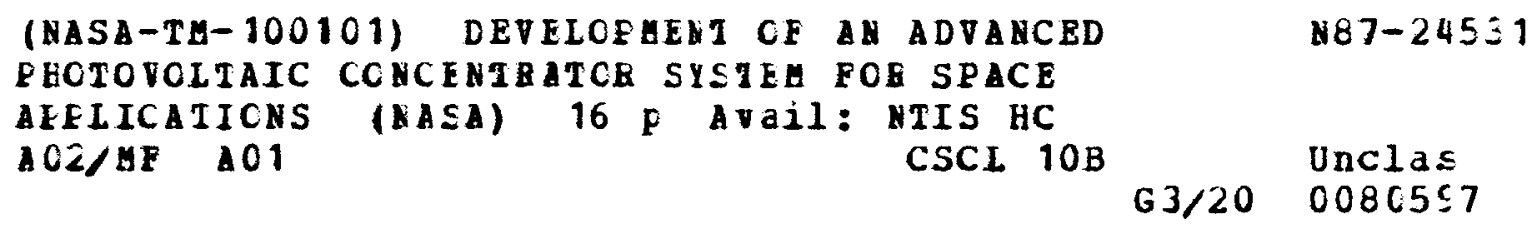

Michael F. Piszczor, Jr.

Lewis Research Center

Cleveland, Ohio

and

Mark J. O’Neill

ENTECH, Inc.

DFW Airport, Texas

Prepared for the

22nd Intersociety Energy Conversion Engineering Conference

cosponsored by the AIAA, ANS, ASME, SAE, IEEE, ACS, and AIChE Philadelphia, Pennsylvania, August 10-14, 1987 
DEVELOPMENT OF AN ADVANCED PHOTOVOLTAIC

CONCENTRATOR SYSTEM FOR SPACE APPLICATIONS

\author{
Michael F. Piszczor, Jr. \\ National Aeronautics and Space Administration \\ Lewis Research Center \\ Cleveland, Ohio 44135 \\ and \\ Mark J. O'Neill \\ ENTECH, Inc. \\ DFW Airport, Texas 75261
}

\begin{abstract}
SUMMARY
Recent studies indicate that significant increases in system performance (increased efficiency and reduced system mass) are possible for high power space-based systems by incorporating current technological developments with photovoltaic power systems. The Advanced Photovoltaic Concentrator Program is an effort to take advantage of recent advancements in refractive optical elements. By using a domed Fresnel lens concentrator and a prismatic cell cover, to eliminate metalization losses, dramatic reductions in the required area and mass over current space photovoltaic systems are possible. The advanced concentrator concept also has significant advantages when compared to solar dynamic Organic Rankine Cycle power systems in Low Earth Orbit applications where energy storage is required. The program is currently involved in the selection of a material for the optical element that will survive the space environment and a demonstration of the system performance of the panel design.
\end{abstract}

INTRODUCTION

Photovoltaic concentrator technology has the potential of yielding very efficient high power systems for a number of space applications. The key to achieving this goal is in minimizing losses throughout the system, especially losses due to optical inefficiencies associated with concentrating the light on the cell. The objective of the Advanced Photovoltaic Concentrator Program at the NASA Lewis Research Center is the development of a highly efficient, relatively lightweight concentrator array which would be applicable to a wide variety of missions. This paper will present the results of a study on the preliminary design of such a system, look at a comparison of the proposed system to other space power systems and discuss the problems and areas of development required for the implementation of the advanced concentrator system.

\title{
ADVANCED PV CONCENTRATOR PROGRAM
}

The purpose of the Advanced Photovoltaic Concentrator Program is to use current technological advancements in optical design and material development to produce a highly efficient PV concentrator array. The basic design should be applicable to a number of mission requirements and be able to survive a wide variety of space environments. 
The design should also be flexible enough to incorporate advances in cell technology as they become avallable. Newer, high efficiency cells should be able to be used in the array with minimal changes to the basic design. These changes may require flexibility in the design of the optical concentration ratio. Another important factor affecting the design of a concentrator system is the pointing accuracy. Strict pointing requirements may limit the size of the array as well as impact the capabilities of the mission itself.

In addition to these design considerations, system complexity, reliability, survivability and redundancy are other factors that must be considered. System mass will be a critical factor for some applications. Mission enabling technology may be the major driver in some instances. Cost, however, will be the major driver in most cases. The goal of the Advanced Photovoltaic Concentrator Program is to develop a high efficiency PV concentrator array while addressing as many of the factors discussed above to as great an extent as possible.

\section{PRELIMINARY DESIGN}

Based on increased design flexibility and the potential for higher optical efficiencies and lower weights, the program is currently investigating refractive optical elements. The preliminary design being considered is based on a concept using a domed Fresnel lens concentrator (ref. 1). This design uses a state-of-the-art $4 \mathrm{~mm}$ diameter gallium arsenide (GaAs) concentrator cell. Figure 1 shows a conceptual design of the domed lens concentrator module. The lens is designed to provide an optical concentration ratio of $100 \mathrm{x}$. Thermal management studies indicate that under these conditions, the cell can be passively cooled and will have an operating temperature of $100{ }^{\circ} \mathrm{C}$.

The design also incorporates a prismatic cell cover to minimize losses due to metalization. The prismatic cover directs the incoming light away from the metalized surface of the cell. The design can accommodate light coming within the $30^{\circ}$ rim angle of the domed Fresnel lens and can essentially eliminate losses due to gridline obscuration up to a metalization coverage of 21 percent (refs. 2 and 3 ). This not only increases the system efficiency by eliminating metalization losses, but also improves the operating cell efficiency by reducing series resistance, which becomes important under higher concentrations.

The domed Fresnel lens uses a curved shape as well as individually designed Fresnel facets along the inner surface. The design maximizes the lens optical efficiency by minimizing reflection losses within the lens by providing equal angles of incidence and emergence from the lens (ref. 4). Initial optical analysis studies indicate that a net lens optical efficiency of 91.5 percent is reasonable without an antireflection coating. Use of a good antireflection coating could further improve the efficiency to 96 percent. The domed fresnel lens can be cut into a square to increase the packing factor of the individual modules and further decrease losses. Figure 2 illustrates the shape and dimensions of the proposed lens design.

The initial studies for both the prismatic cover and domed fresnel lens were based on use of the material KEL-F 81, which has an average index of refraction of 1.43 . If this material were unsuitable for space, the lens and 
prism cover design could be modified to maximize system efficiency for the parameters of the new material. Since the basic design is flexible enough to incorporate these new parameters, changes to the net system optical efficiency due to a material change are expected to be minimal.

The module design was developed to provide a $7^{\circ}$ tracking requirement while maintaining the minimum 91.5 percent optical efficiency. Larger tracking errors could be accommodated by increasing the size of the cell. However, using this design method would decrease efficiency due to nonuniform illumination of the cell. The studies indicate that tracking errors up to $4^{\circ}$ could be designed into the system without having a large detrimental effect on the cell efficiency.

Figure 3 illustrates the individual modules incorporated into a panel design. Using the estimates on system performance obtained through detalled optical and cell analyses, a module providing $236 \mathrm{~W} / \mathrm{m}^{2}$ and $74 \mathrm{~W} / \mathrm{kg}$ could be achieved based on the current technology available. These numbers include the support and deployment structure. A proposed deployment structure for the domed Fresnel lens concentrator array is shown in figure 4. With improvements to the lens by use of an antireflection coating and the use of recently deve1oped improvements to the GaAs cells, the system performance can be improved to $278 \mathrm{~W} / \mathrm{m}^{2}$ and $87 \mathrm{~W} / \mathrm{kg}$. The expected performance is repeated in table I along with the system parameters used to obtain these values. The array mass is based on the use of $\mathrm{Kel-F} 81$ as the lens material.

\section{SYSTEM COMPARISONS}

Based on realistic estimates of the efficiency and mass for the domed Fresnel lens provided in table I, the advanced photovoltaic concentrator concept shows the potential for significant improvements in both array area and mass reduction when compared to other PV technologies. The advanced concentrator using current GaAs cell technology. AdvCon-GaAs, was compared to three other present day technologies: (1) TDRS, Tracking \& Data Relay Satellite silicon array technology; (2) OAST-1, large area silicon array technology flown in 1984 on the STS-410 shuttle mission; and (3) MCC, the TRW Miniature Cassegrainian Concentrator array technology. For the basis of this comparison, both the MCC and the AdvCon-GaAs are based on the same GaAs cell technology, however the advanced concentrator benefits from the addition of the prismatic cell cover to eliminate gridline losses.

Since the advanced concentrator is designed to be essentially independent of the type of cell technology used, an additional advanced concentrator system was used for the comparison, AdvCon-30\%. This system includes improvements to the lens technology (see table I) and uses a 30 percent photovoltaic cell. Such a cell has yet to be demonstrated, but the development of a cascade structure with a 30 percent conversion efficiency is not unreasonable.

Figures 5 and 6 compare the area and mass requirements of the different technologies respectively. A significant increase in the array efficiency of the advanced concentrator shows a dramatic 54 percent decrease in specific area compared to OAST-1 silicon array technology. The specific area is decreased to 68 percent if the comparison is made to an improved advanced concentrator using a 30 percent cell. Since both concentrator systems, MCC and 
AdvCon-GaAs, are based on the same cell technology, specific area improvements, which result in a 33 percent size reduction, are solely based on the better packing factor and optical efficiency of the advanced concentrator system.

In regard to system mass, the advanced concentrator is approximately the same as large area silicon array technology and significantly lighter than current PV concentrator technology. Improvements to the advanced concentrator system, Advcon-30\%, reduces the specific mass further by reducing the area required for a given delivered power. The specific mass comparisons include the supporting array structure and do not include energy storage.

With the advent of space station, large area, high power systems have received considerable attention. For such Low Earth Orbit (LEO) applications, photovoltaic power systems require energy storage during the eclipse phase of the orbit to supply continuous power. The requirements for energy storage usually drive up the size and weight of PV systems significantly. In order to better understand the applicability of the advanced concentrator concept to high power LEO applications, both the AdvCon-GaAs and the AdvCon-30\% technologies were compared to the two current systems being considered for space station: large area silicon cell technology (ref. 5 )(Si) and the solar dynamic Organic Rankine Cycle (ORC) power system.

The system comparisons include power management and distribution (PMAD) and energy storage losses. The mass comparison includes the PV structure and deployment mechanism as well as energy storage. PMAD masses are not included. The data for the solar dynamic Organic Rankine Cycle system is based on the current design for space station (ref. 6). The specific area for the solar dynamic system includes only the solar intercept area and does not include the area required for waste heat radiators. The advanced concentrator and silicon PV systems are passively cooled with the support structure acting as the radiator.

The Si, AdvCon-GaAs and AdvCon-30\% photovoltaic systems use an energy storage system based on nickel-hydrogen batteries with a 70 percent round-trip efficiency and a net energy capacity of $13.9 \mathrm{~W}-\mathrm{hr} / \mathrm{kg}$ (ref. 7 ). To determine to impact of battery improvements on the system, the AdvCon-30\% system with an advanced sodium-sulfur battery (AdvCon-NaS) was also included. The sodiumsulfur battery was assumed to have an 80 percent round-trip efficiency and a net energy capacity of $100 \mathrm{~W}-\mathrm{hr} / \mathrm{kg}$.

The comparisons illustrate that the advanced concentrator concept has the potential for significant improvements in system performance over the other two systems. Figures 7 and 8 11lustrate the area and mass comparisons respectively. The advanced concentrator represents a large reduction in area over the silicon array technology while maintaining approximately the same mass. The current advanced concentrator technology. AdvCon-GaAs, represents approximately the same solar intercept area as the solar dynamic system while achieving a 73 percent reduction in mass over that system. Further improvements to the specific area and mass could be achieved by incorporating an improved advanced concentrator and an advanced energy storage system, such as the sodium-sulfur battery.

The above comparison indicates that the advanced concentrator concept is applicable to large area, high power space systems in Low Earth Orbit. 
Figure 9 illustrates, to scale, what growth space station, requiring $300 \mathrm{~kW}$ bus power, would look like if it were powered by advanced photovoltaic concentrator arrays with a 30 percent cell.

\section{PROGRAM STATUS AND DEVELOPMENT}

To date, the Advanced Photovoltaic Concentrator Program has been limited to analytical studies on the domed Fresnel lens concept and certain experimental results based on terrestrial PV systems. Based on previous experience with terrestrial PV systems, the results predicted by the analytical studies for space qualified systems seem achievable.

The major concern, however, resides in the choice of material for the concentrator and prismatic cover. Materials currently used for terrestrial programs probably will not survive under the extreme conditions posed in space. The material used in the preliminary study, KEL-F 81 , has been tested for atomic oxygen exposure. Atomic oxygen exposure could be a major problem for certain LEO applications. The results of the test indicate that the material would probably not fulf 111 lifetime requirements unless properly treated. Tests for ultraviolet radiation exposure are required to determine the applicability of the optical material for other types of missions. The effect of the module from natural radiation and the amount of protection of fered to the cell from the module must also be determined.

Environmental survivability could be ensured by either the choice of a proper optical material or use of a suitable coating. A key to the flexibility of the advanced concentrator concept is that the system performance is not strongly dependent on the optical material chosen. Changes due to differences in the optical properties of the material chosen can be incorporated into the lens design and have little effect the expected system performance.

To answer some of the concerns regarding the development of a space qualified advanced concentrator system, a program is being established to heip determine the following issues:

Optical material selection and stability

Module efficiency

Off-axis tracking efficiency

Thermal cycling

Ultraviolet radiation survivability

Atomic oxygen survivability

Natural radiation survivability

Structural integrity

Current plans call for the development of a number of individual elements and a prototype pane1. Current emphasis in the program is being placed on the 
demonstration of the overall system efficiency of the panel design and the selection of a suitable optical material.

\section{SUMMARY OF RESULTS}

The studies conducted to date indicate that significant increases in system efficiency and reductions in system mass are possible using the advanced photovoltaic concentrator concept. By using a domed Fresnel lens concentrator and a prismatic cell cover to eliminate metalization losses, dramatic improvements over current space photovoltaic systems are possible. The advanced concentrator concept also has significant advantages when compared to solar dynamic Organic Rankine Cycle power systems in Low Earth Orbit applications where energy storage is required. The program is currently involved in the selection of a material for the optical element that will survive the space environment and a demonstration of the system performance of the panel design.

\section{REFERENCES}

1. O'Ne111, M.J., Walters, R.R., and McDanal, A.J., "Development of a Fresnel Lens Gallium Arsenide Photovoltaic Concentrator for Space Applications," ENTECH, Inc., Dallas-Fort Worth Airport, TX, September 1986.

2. 0'Nei11, M.3., "Two Linear Fresnel Lens Photovoltaic Concentrator Design Innovations: A Prismatic Cell Cover and a Copper Heat Spreader," DOE/ER/80126-1, ENTECH InC., April 1985.

3. King, D., "Silicon Cell Research Overview," Photovoltaic Concentrator Technology Project, Fourteenth Project Integration Meeting, SAND86-0058/1, Sandia National Laboratories, 1986, pp. 91-100.

4. O'Neill, M.J., "Solar Concentrator and Energy Collection System," U.S. Patent No. 4,069,812, Jan. 24, 1978.

5. Elms, R.V., "Solar Arrays for Space Station and Platforms," Advancing Toward Technology Breakout in Energy Conversion (21st IECEC), Vol. 3, American Chemical Society, Washington D.C., 1986, pp. 1898-1902.

6. "Space Station WP-04 Power System," Preliminary Analysis and Design Document DR-02, Vo1. 1, Rocketdyne Div., Rockwell Internationa1, Canoga Park, CA. Dec. 1986.

7. Manzo, M.A. and Hoberecht, M.A., "A $37.5 \mathrm{~kW}$ Point Design Comparison of the Nickel-Cadmi um Battery, Bipolar Nickel-Hydrogen Battery, and Regenerative Hydrogen-0xygen Fue 1 Ce11 Energy Storage Subsystems for Low Earth Orbit," Advanced Energy Systems - Their Role in Our Future (19th IECEC), Vo1. 1, American Nuclear Society, LaGrange Park, IL, 1984, pp. 287-294. (NASA TM-83651). 
TABLE 1. - SYSTEM PERFORMANCE OF DOMED FRESNEL LENS CONCENTRATOR USING CURRENT AND IMPROVED TECHNOLOGY

\begin{tabular}{|c|c|c|}
\hline System & Current & Improved \\
\hline $\begin{array}{l}\text { Lens optical efficiency, } \\
\text { percent }\end{array}$ & 91.5 & 96.0 \\
\hline $\begin{array}{l}\text { Cell efficiencya } \\
\text { (at } 100{ }^{\circ} \mathrm{C}, 100 \text { suns), } \\
\text { percent }\end{array}$ & 21.4 & 24.0 \\
\hline $\begin{array}{l}\text { Lens/panel packing factor, } \\
\text { percent }\end{array}$ & 97.0 & 97.0 \\
\hline $\begin{array}{l}\text { Wiring/mismatch factor, } \\
\text { percent }\end{array}$ & 92.0 & 92.0 \\
\hline Array efficiency, percent & 17.5 & 20.6 \\
\hline Array output, $w / m^{2}$ & 236 & 278 \\
\hline Panel mass, $\mathrm{kg} / \mathrm{m}^{2}$ & 2.5 & 2.5 \\
\hline Structure mass, $\mathrm{kg} / \mathrm{m}^{2}$ & 0.7 & 0.7 \\
\hline Array mass, $\mathrm{kg} / \mathrm{m}^{2}$ & 3.2 & 3.2 \\
\hline Power/mass, W/kg & 74 & 87 \\
\hline
\end{tabular}

aGaAs cell technology which includes prismatic cell cover to reduce metalization losses. 


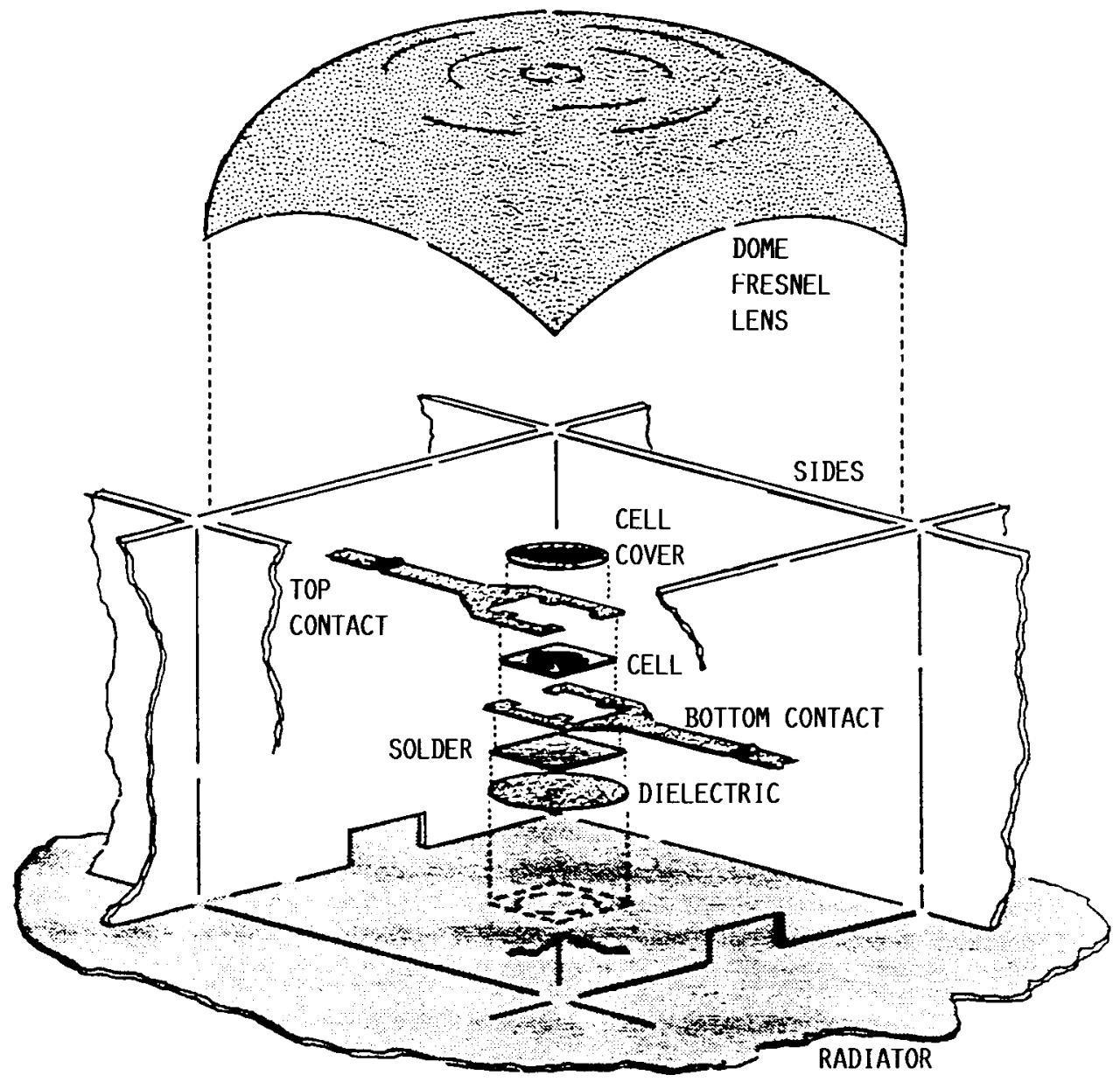

FIGURE 1. - DOMED FRESNEL LENS MODULE CONCEPTUAL DESIGN. 


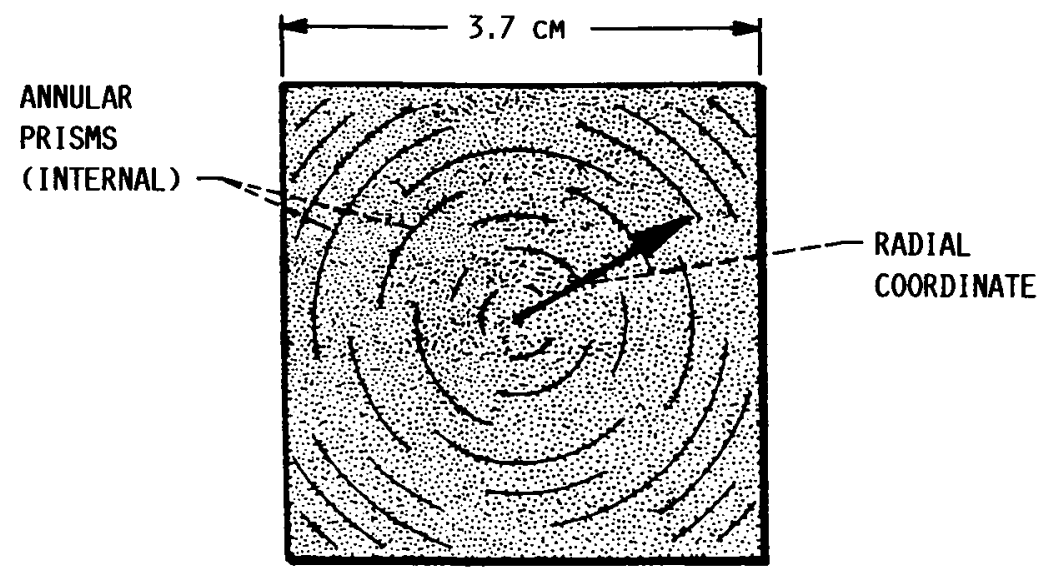

ANNULAR

PRISMS

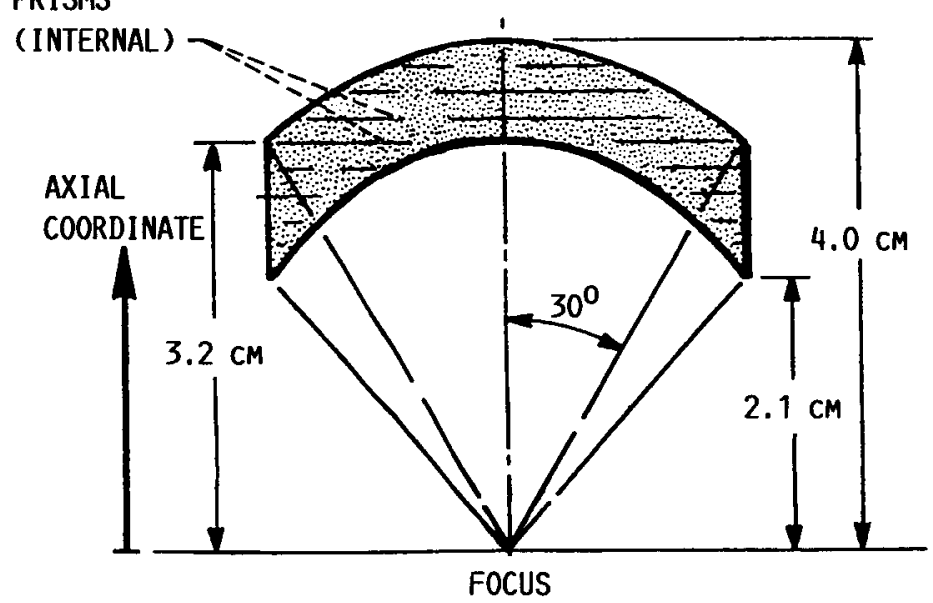

FIGURE 2. - DOMED FRESNEL LENS DESIGN. 


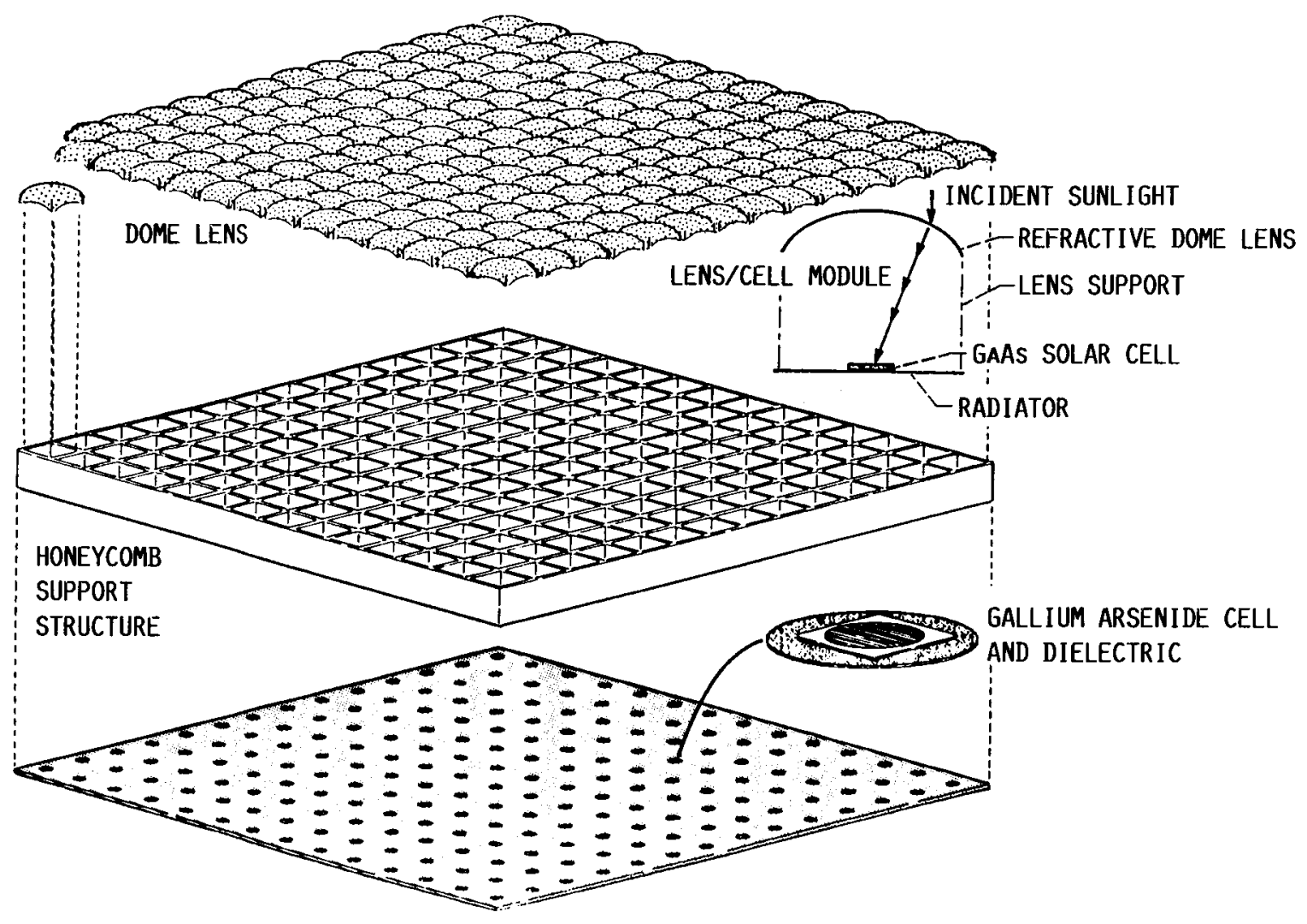

FIGURE 3. - DOMED FRESNEL LENS PV CONCENTRATOR PANEL DESIGN. 


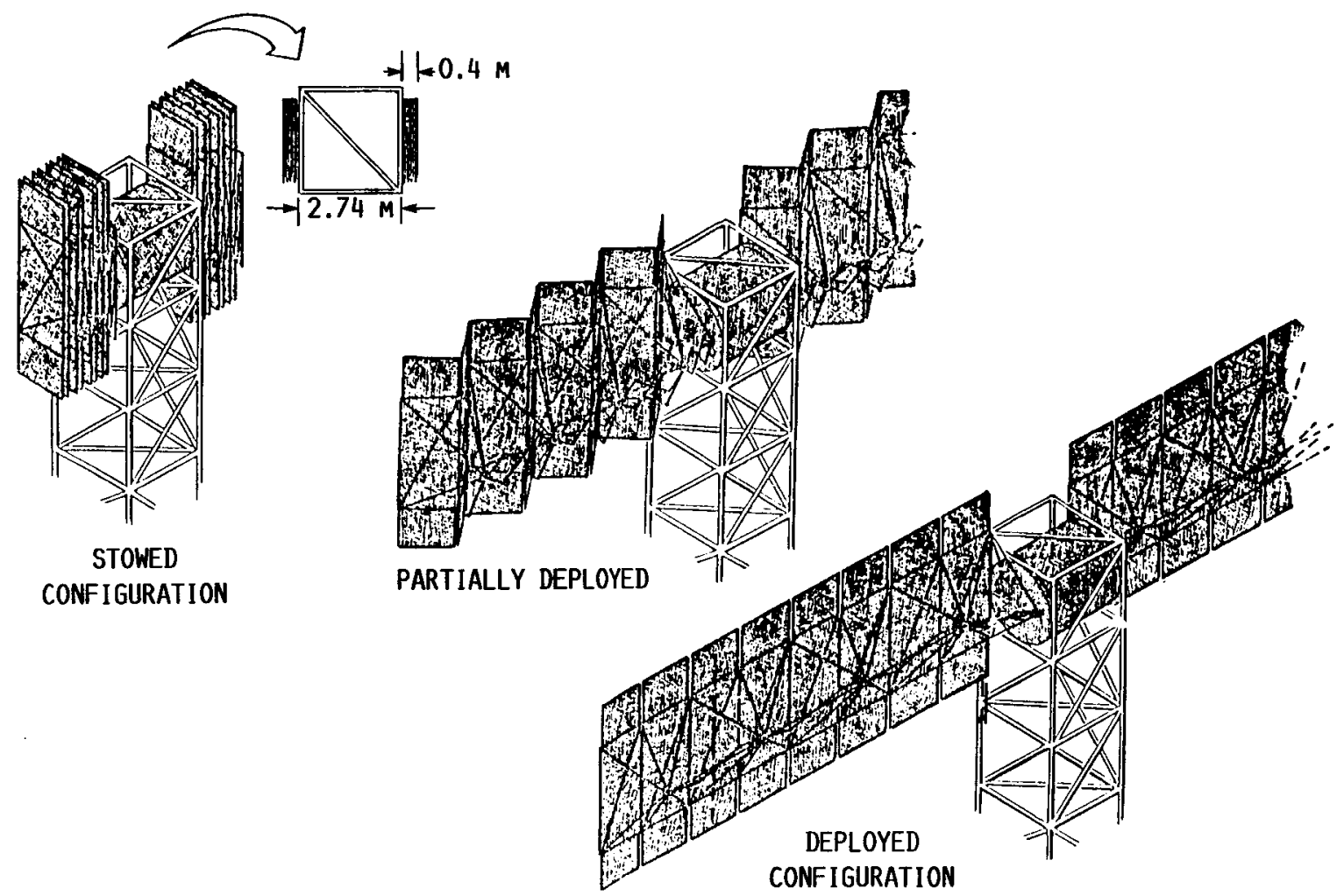

FIGURE 4. - PROPOSED DEPLOYMENT STRUCTURE FOR DOMED FRESNEL LENS PV CONCENTRATOR. 


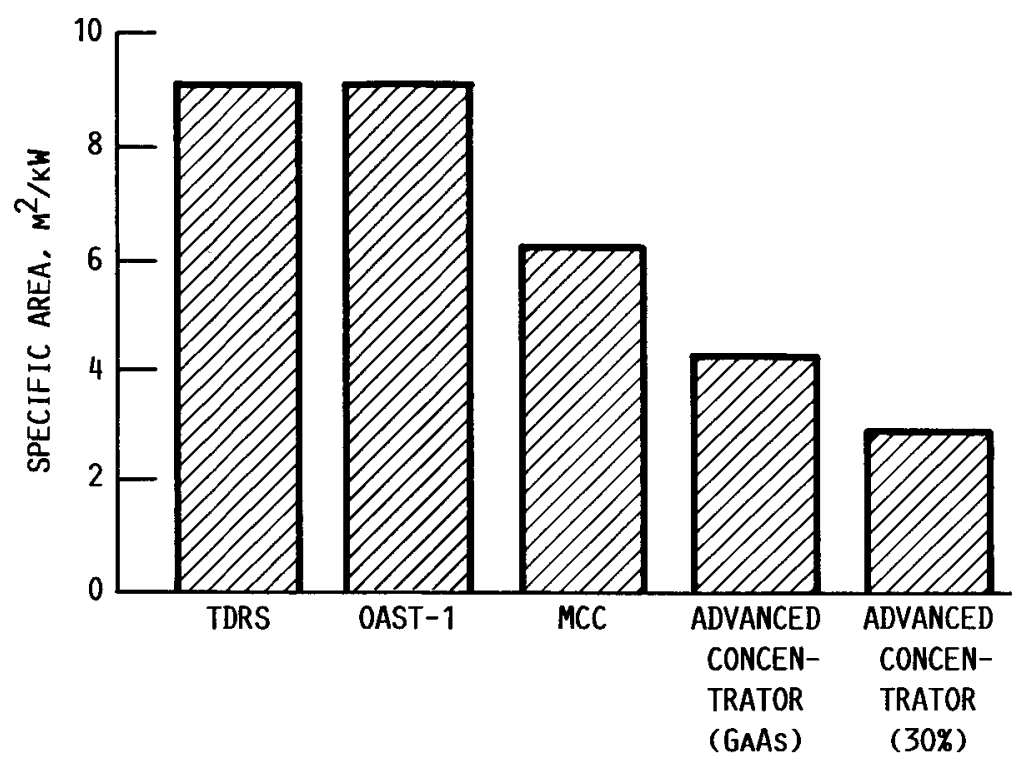

FIGURE 5.- SPECIFIC AREA COMPARISON OF THE ADVANCED CONCENTRATOR SYSTEM TO CURRENT PV SYSTEMS.

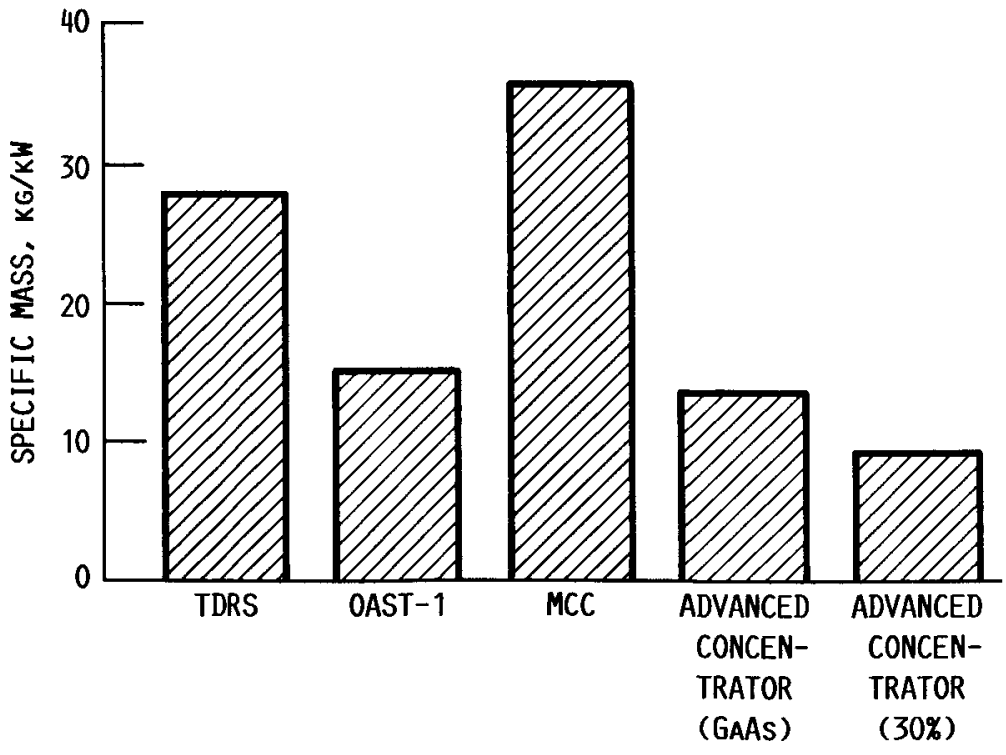

FIGURE 6. - SPECIFIC MASS COMPARISON OF THE ADVANCED CONCENTRATOR SYSTEM TO CURRENT PV SYSTEMS. 


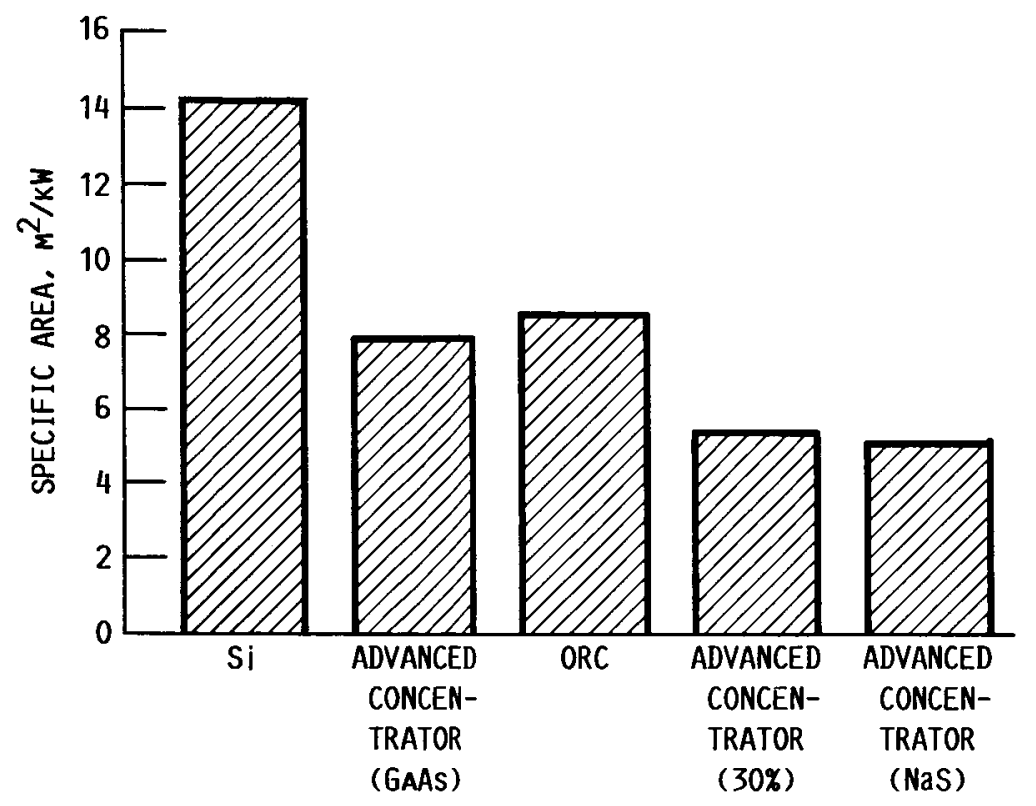

FIGURE 7. - AREA COMPARISON OF PV SILICON, ADVANCED CONCENTRATOR AND SOLAR DYNAMIC ORGANIC RANKINE CYCLE POWER SYSTEMS FOR LOW EARTH ORBIT APPLICATIONS.

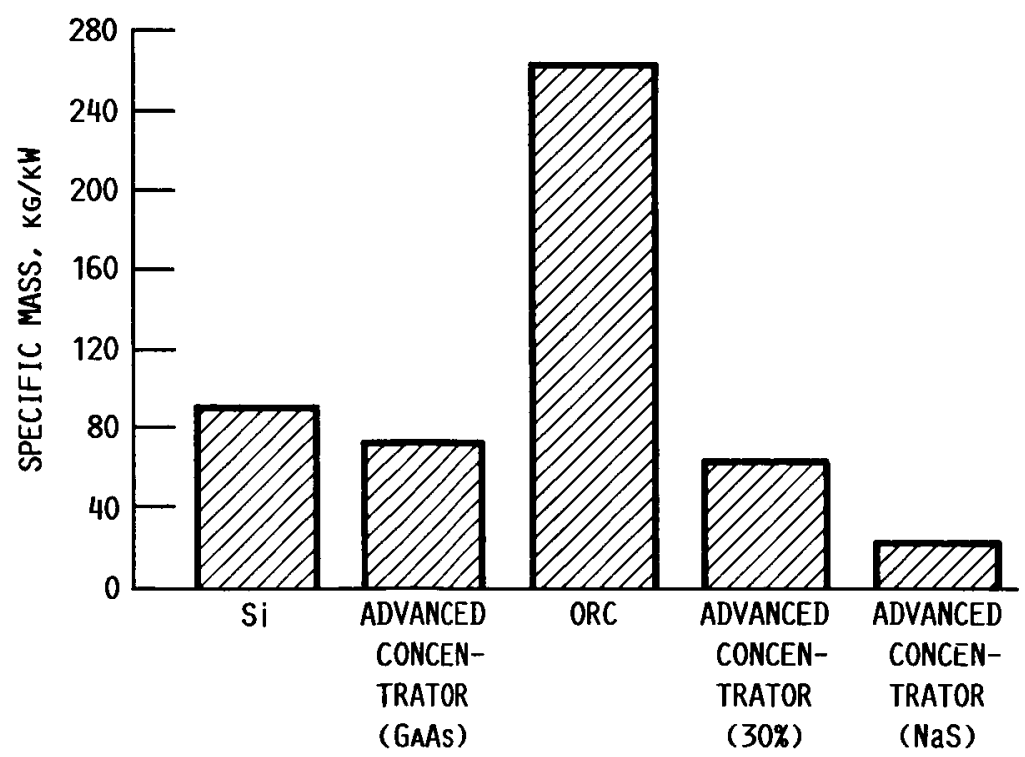

FIGURE 8. - MASS COMPARISON OF PV SILICON, ADVANCED CONCENTRATOR AND SOLAR DYNAMIC ORGANIC RANKINE CYCLE POWER SYSTEMS FOR LOW EARTH ORBIT APPLICATIONS. 


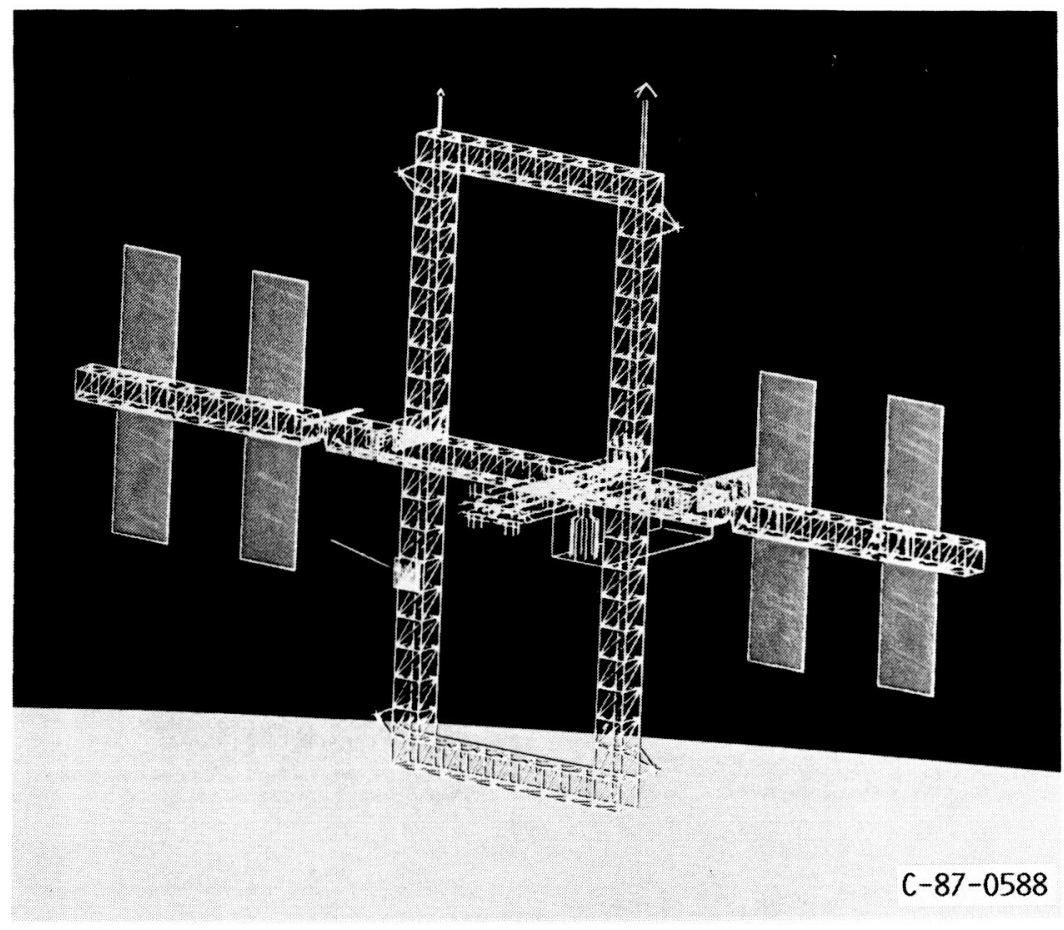

FIGURE 9. - SPACE STATION WITH A 300-KW POWER SYSTEM USING AN ADVANCED PV CONCENTRATOR WITH 30\% CELLS. 


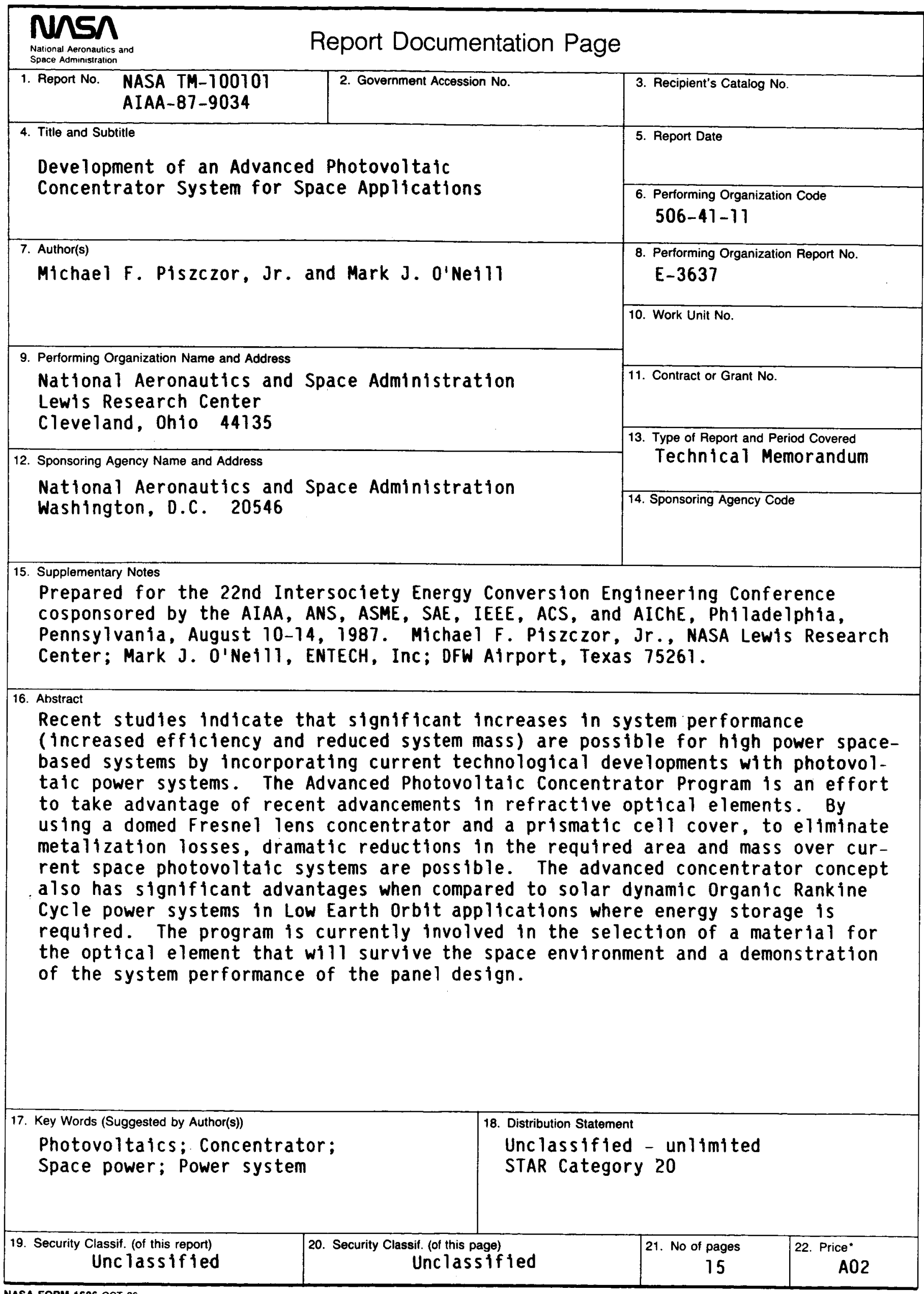

